\title{
Design of an Instrument for Liquid Level Measurement and Concentration Analysis Using Multisensor Data Fusion
}

\author{
K. V. Santhosh $\mathbb{D}^{1},{ }^{1}$ Blessy Joy, ${ }^{1}$ and Swetha Rao $\mathbb{D}^{2}$ \\ ${ }^{1}$ Centre for Cyber Physical System, Department of Instrumentation and Control, Manipal Institute of Technology, Manipal Academy \\ of Higher Education, 576104, India \\ ${ }^{2}$ Institute of Automation, University of Bremen, 28359, Germany
}

Correspondence should be addressed to Swetha Rao; swetha@uni-bremen.de

Received 1 August 2019; Revised 22 October 2019; Accepted 17 December 2019; Published 6 January 2020

Academic Editor: Stelios M. Potirakis

Copyright ( 92020 K. V. Santhosh et al. This is an open access article distributed under the Creative Commons Attribution License, which permits unrestricted use, distribution, and reproduction in any medium, provided the original work is properly cited.

This paper presents the design of an instrument for measuring the liquid level. The objective of this proposed work is to measure the level of liquid accurately even with variations in liquid concentration. The designed instrument should also be able to compute the concentration of additives in the liquid. For this purpose, a multisensor model comprising a capacitive level sensor (CLS), ultrasonic level sensor (ULS), and capacitance pressure sensor is used to acquire information of the liquid. The data acquired from all these sensors are processed using Pau's multisensor data fusion framework to compute the level of liquid along with the concentration of additives added to the solution. Pau's framework consists of alignment, association function, analysis, and representation functions. The designed multisensor technique is tested with real-life data for varying liquid levels and additives. The results obtained show that the successful implementation of the proposed objective producing a root mean square of percentage error is $1.1 \%$ over the full scale is possible.

\section{Introduction}

The level process is one of the most commonly found processes in any process industry, like the diary, pharmacy, fabric, petroleum, and confectionary. The liquid process ideally involves control of the liquid level in a container under a dynamic or static condition with the set point level as desired by the user. The controller is implemented to obtain the desired set point by actuating the final control element. To design a controller, an instrument is needed to measure the actual liquid level. This instrument is a device used to measure physical parameters, in this case, liquid level.

Many measurement techniques are available for liquid level measurement; a detailed study of available measurement techniques is reported. Several liquid measurement techniques such as capacitance and conductive are analysed in [1]. A technique for liquid level measurement using multiple capacitive sensors to increase the sensitivity of measurement is reported in [2]. Analysis of capacitive liquid level sensor characteristics for fuel measurement in a level control process used in the upper-stage rocket system is reported in [3]. Design and development of semicylindrical capacitor for measurement of liquid level is reported in [4]. In [5], the principle of variation in conductivity of an electrode with variation in liquid level is used for measurement of liquid. Image processing technique used to compute the level of liquid from the captured image of the container is reported in $[6,7]$. Measurement of liquid level in a distillation process using a digital camera is discussed in [8]. Paper [9] discusses the technique of liquid level measurement based on the reflective principle of light. Change in the total internal reflection of light passing through the optical fiber varies with a change in liquid, which is utilized in [10] for measuring the liquid level. In [11], a reflected acoustic wave is analysed to compute the level of the liquid. Paper [12] reported the analysis of radiated frequency-modulated millimeter wave through a container with liquid for measurement of liquid level measurement. Time-domain reflectometry is analysed to compute the level of liquid in [13]. In [14], refractive index analysis via coreless multimode fiber is carried on to compute 
the level of liquid in a container. Paper [15] reports measurement of liquid level by intercepting signal to the controller using wavelet packet transform. Design and evaluation of a capacitance water level sensor are discussed in [16]. In [17], the design and analysis of coaxial cylindrical CLS, which is used to measure the level of conductive liquid, are reported. Monitoring the wavelength shift caused by a multimode interface in a no core fiber for measurement of liquid level is discussed in [18]. Paper [19] reports the design of a Mach-Zehnder interferometer formed by sandwiching photonic crystal fiber to measure the level of the liquid. Echo from the liquid surface and wire immersed in the liquid are analysed to detect changes in propagation speed. This change is used to measure the liquid level in [20]. The acoustic response was detected to measure the penetration depth by comparing the true value and the Helmholtz resonance frequency in [21]. Paper [22] discusses the implementation of a comb-type capacitor design for improved sensitivity in liquid level measurement. Optical fiber is used to measure the dynamic level of liquid in [23]. Paper [24] discusses the design of printed resonator used to measure the level of the liquid. Optical fibre is used to measure the level of liquid in the cryogenic propellant tank [25] and paper [26] uses a charged couple to measure the radiation reflected from the surface thereby measuring the level of the liquid. Although a lot of liquid level measuring instruments have been reported in the literature, they are confined to a particular measurement and are often calibrated under defined boundary conditions.

Few papers have reported on the effect of internal parameters on the measurement such as in paper [27] that discusses the effect of humidity on the capacitance sensor output. The effect of crude palm oil composition on electrical capacitance is analysed in [28]. Water permeation in organic coatings is measured by computing change in capacitance across the parallel plate electrodes in [29]. Measurement of moisture content in a solid structure by using a capacitance-based sensor is reported in [30]. In [31], the effect of the oil-water mixture on the capacitance sensor output is analysed to characterize the two-phase flow. Double helix capacitance is used to measure the liquid holdup in oil-water two-phase flow pipers in [32]. Density profile analysis is carried on using a capacitance sensor for a vibrated granular bed in [33]. In [34], pressure sensors are used to measure liquid level by measuring the density of a liquid. In [35], the liquid level is measured indirectly by measuring pressure exerted on a tube by the change in the liquid level. This paper also discussed the effect of temperature on measurement. Similarly, the effect of temperature on fiber Bragg grating sensor used for measurement of liquid level is discussed in [36]. Effect of change in liquid temperature on level measurement by capacitance level sensor is discussed in [37]. Effect of sensor placement on measurement when an acoustic sensor is used for measurement of liquid level is reported in [38]. In [39], liquid level measurement based on reflection guidance mechanism by using a silica tube is discussed. This technique also discusses its robustness towards temperature changes. Detailed analysis from the available literature gives us the information that output of capacitance liquid level sensor is not just the

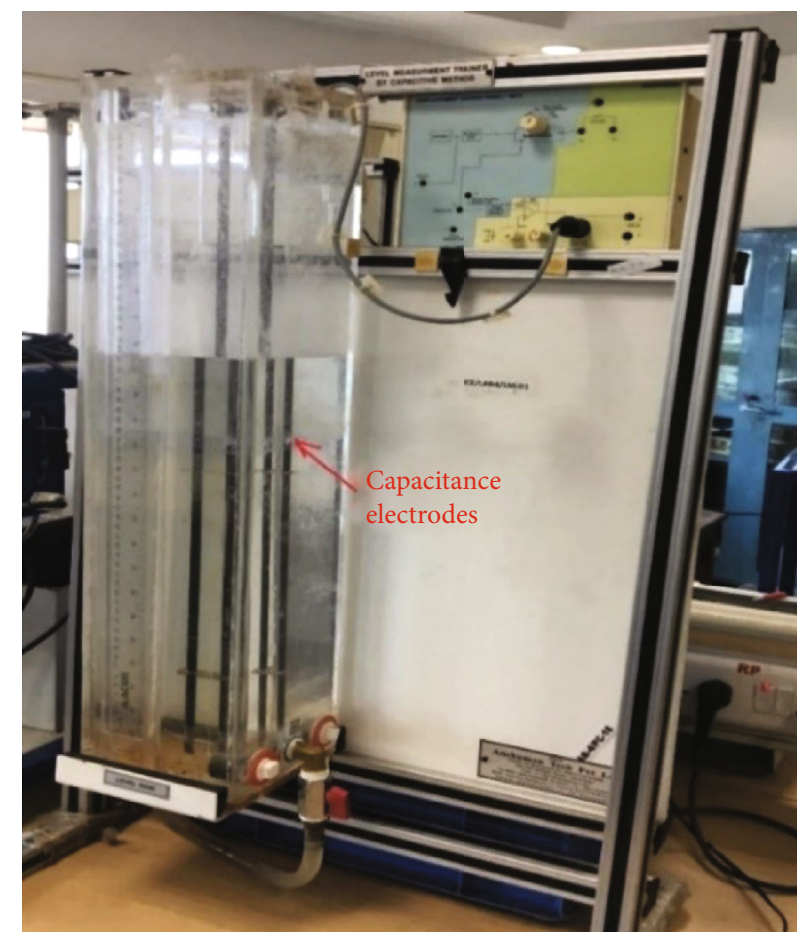

Figure 1: Experimental setup.

function of liquid level but also gets affected by the type of liquid, temperature of liquid, composition of liquid, etc. The above reported characteristics of capacitance level sensor are put to use in this proposed work to measure liquid level along with the concentration of soluble mixed in the liquid solution.

\section{Experimental Setup}

The experimental setup consists of a tank in which the liquid is stored. To measure the level of liquid, a capacitive level sensor is used. The output of this sensor is connected to a signal conditioning circuit to convert the output signal into a standard voltage signal. The voltage signal is then acquired using a NI myRIO board, as shown in Figure 1.

The equation for the capacitance level sensor is derived from the basic principles of capacitance, where the capacitance between two parallel plates can be given in Equation (1) $[40,41]$.

$$
C=\frac{\epsilon_{0} \epsilon_{\mathrm{r}} A}{d}
$$

where " $A$ " is the cross-sectional area of the plates, " $d$ " is the distance between two plates, " $\epsilon_{0}$ " is the permittivity of air, and " $\epsilon_{\mathrm{r}}$ " is the permittivity of liquid. If there is a change in the dielectric element, the capacitance will change accordingly.

In the proposed work, the capacitance level sensor is designed considering two parallel cylindrical rods that act 


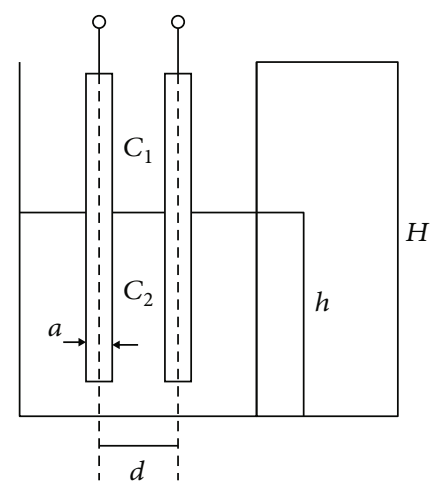

Figure 2: Schematic of the capacitance level sensor.

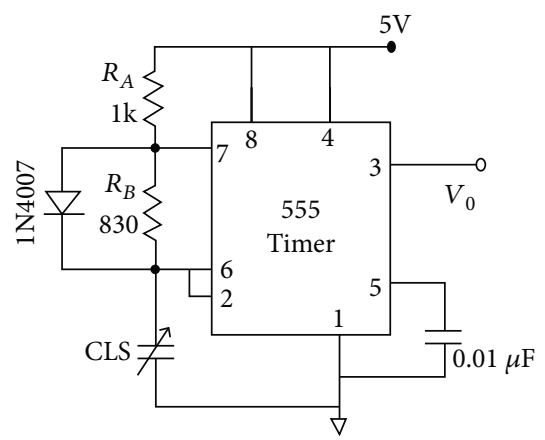

Figure 3: Circuit diagram of the timer.

as electrodes instead of parallel plates. The choice of this structure is for the ease of maintenance and for improved ruggedness as shown in Figure 2.

Total capacitance $C$ is given by [42]

$$
C=\frac{\pi \varepsilon_{\mathrm{o}}(H-h)}{\ln [(d-a) / a]}+\frac{\pi \varepsilon_{\mathrm{o}} \varepsilon_{\mathrm{r}} h}{\ln [(d-a) / a]},
$$

where $C$ is the total capacitance, $\varepsilon_{0}$ is the vacuum permittivity, $\varepsilon_{\mathrm{r}}$ is the relative permittivity of water, $d$ is the distance between electrodes, $a$ is the electrode radius, $h$ is the liquid level, and $H$ is the electrode and tank height.

In the experimental setup considered for the proposed work, the dimensions of the capacitive level sensor are the distance between the electrodes $d=0.0088 \mathrm{~m}$, radius of electrodes $a=0.0015 \mathrm{~m}$, and the full height of the tank $H=0.66 \mathrm{~m}$.

To convert the CLS output to voltage, a timer circuit and frequency to voltage conversion circuit is used. Timer circuit consists of a 555 IC as shown in Figure 3, and frequency to voltage conversion achieved using LM331 IC and a conversion circuit as shown in Figure 4. The outputs obtained from the timer circuit and frequency to voltage circuit is represented using Equation (3) and Equation (4), respectively. The output voltage is then acquired on to the computer using an analogue channel of NI myRIO (National Instruments Reconfigurable Input-Output Embedded Boards). The datasheets for 555 IC and LM331 IC provide the following equations. Figure 5 shows the practical implementation of

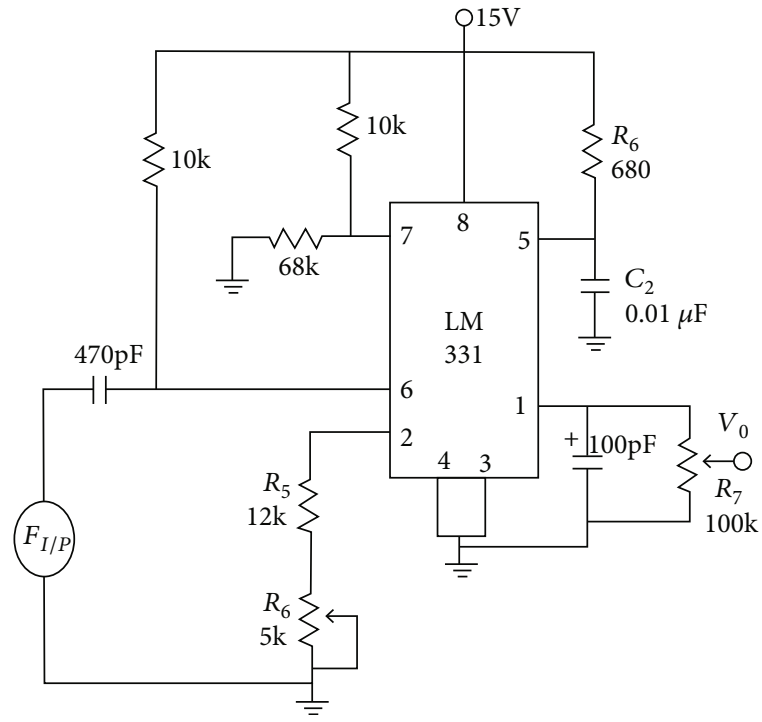

Figure 4: Circuit diagram of frequency to voltage converter.

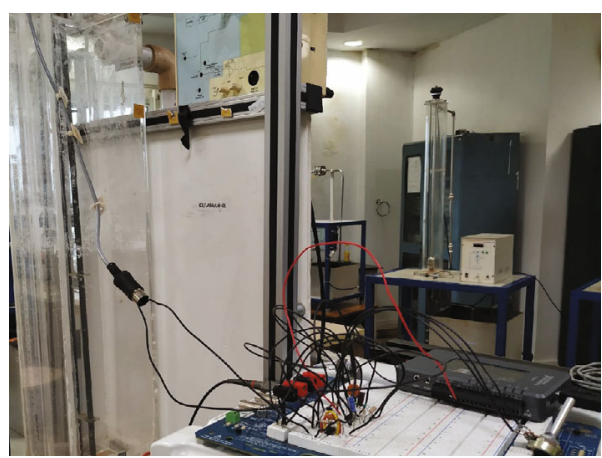

Figure 5: Practical setup for signal conditioning and acquisition.

the circuit for acquiring the capacitance and converting to voltage to acquire to PC by data acquisition devices [43].

$$
\begin{aligned}
f_{i / p} & =\frac{1}{\ln (2)\left(R_{A}+2 R_{B}\right) C} \mathrm{~Hz}, \\
V_{O / P} & =\left(\frac{R_{7}}{R_{5}+R_{6}}\right) \times 2.09 \times R_{4} \times C_{2} \times F_{I / P} \mathrm{~V} .
\end{aligned}
$$

\section{Problem Statement}

The above section shows how the experimental setup is designed. The experimental setup is subjected to varying levels of liquid and the output obtained is plotted. For experimentation, we use water and the output obtained for different levels is acquired by NI myRIO and the plot is as shown in Figure 6. From the highlighted region in characteristic plot of capacitance level sensor, as shown in Figure 6, it can be noted that a part of the initial range of measurement has a higher nonlinearity. This effect in the measurement is relative to the mechanical design of the electrode as can be seen in Figure 7 of the electrodes used.

To understand the effect of solution concentration on the output of a capacitance sensor, water is replaced by the sugar 


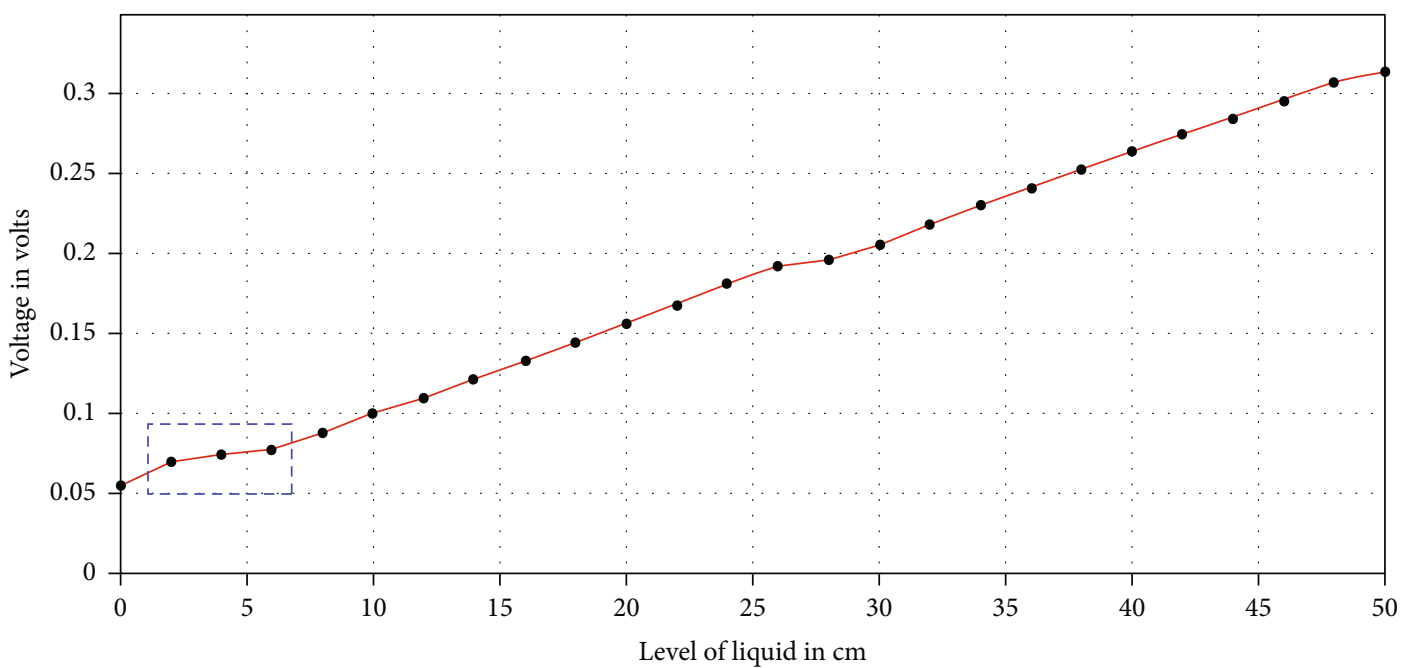

FIGURE 6: Output of capacitance level sensor for variation of liquid level.

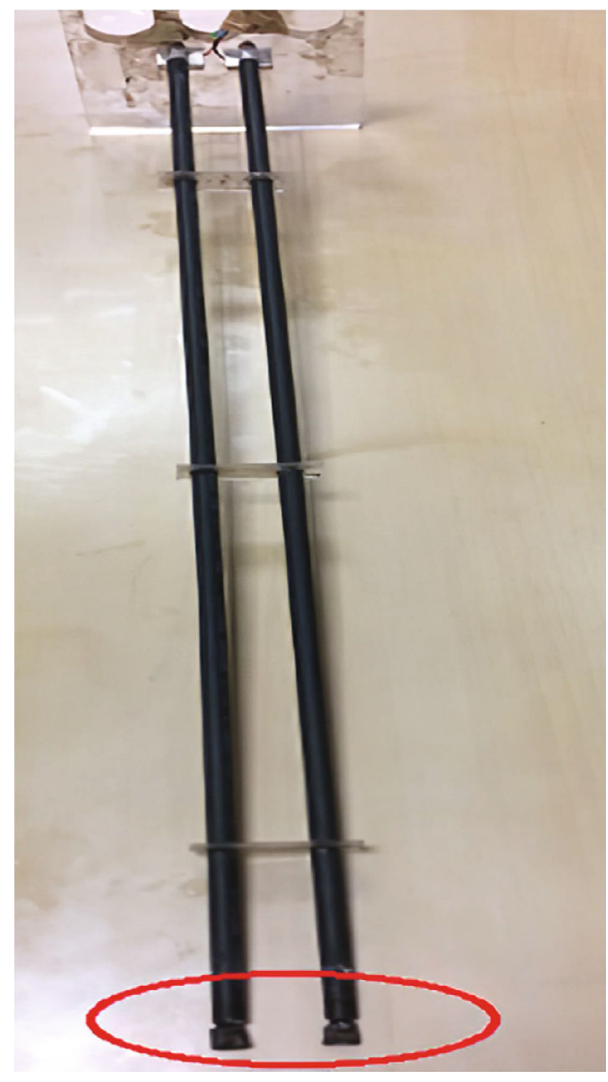

Figure 7: Capacitance electrodes for liquid level measurement.

solution. Test result obtained for the same is as shown in Table 1 and the complete changes in terms of capacitance, frequency, and voltages are shown in Table 2. A similar analysis is carried out for the variation in liquid concentration by the addition of $10 \%, 20 \%$, and $30 \%$ of the sugar solution. Figure 8 shows the variations of CLS output with changes in concentration and liquid level. From Table 1, it is clear that the output of capacitance is a function of liquid level and the property of liquid (permittivity). This property of the capac-
TABle 1: Change in permittivity with a change in sugar concentration.

\begin{tabular}{lc}
\hline Weight of sugar $(\mathrm{gms}) /$ ltr of water & Permittivity at $25^{\circ} \mathrm{C}$ \\
\hline 0 & 78.54 \\
10 & 76.19 \\
20 & 73.65 \\
30 & 70.70 \\
40 & 67.72 \\
50 & 64.20 \\
60 & 60.19 \\
\hline
\end{tabular}

itance level sensor is used in the proposed work to design a multisensor system which can measure the level of liquid and in addition indicate details about the concentration of liquid under consideration.

\section{Problem Solution}

To achieve the objective of measuring the liquid level and the concentration simultaneously, a multisensor system is incorporated in addition to using the available capacitance level sensor. Two additional sensors, an ultrasonic level sensor and a pressure sensor, are placed on the container in which the liquid level is being measured, as shown in Figure 9. We consider a transit-type ultrasonic level sensor, which measures the level of liquid based on the time taken for the signal to travel from the sensor and back again. This value would be a direct indicator of the liquid level and will not vary with the type of liquid. In addition, a pressure sensor is also used in the experiment, which will measure the liquid level based on the density of the liquid.

The data acquired from these three sensors are combined using Pau's framework [44]. The block diagram in Figure 10 shows the process flow for data fusion using Pau's. The first stage in the data fusion process is data alignment. In this 
TABLE 2: Output of capacitance level sensor for variation of solution concentration.

\begin{tabular}{|c|c|c|c|}
\hline \multicolumn{4}{|l|}{ Case 1: plain solution } \\
\hline Change in liquid level (in m) & Sensor output $(\mathrm{nF})$ & Timer output (MHz) & Frequency to voltage converter output (V) \\
\hline 0.10 & 17.05 & 26.3 & 0.1 \\
\hline 0.20 & 27.29 & 16.2 & 0.156 \\
\hline 0.30 & 39.99 & 11.0 & 0.204 \\
\hline 0.40 & 51.64 & 8.5 & 0.264 \\
\hline 0.50 & 63.2 & 6.8 & 0.314 \\
\hline \multicolumn{4}{|c|}{ Case $2: 10 \%$ concentrated sugar solution } \\
\hline Change in liquid level (in m) & Sensor output (nF) & Timer output $(\mathrm{kHz})$ & Frequency to voltage converter output (V) \\
\hline 0.10 & 16.22 & 26.8 & 0.093 \\
\hline 0.20 & 26.1 & 16.6 & 0.15 \\
\hline 0.30 & 38.36 & 11.3 & 0.203 \\
\hline 0.40 & 49.61 & 8.8 & 0.265 \\
\hline 0.50 & 61.1 & 7.1 & 0.324 \\
\hline \multicolumn{4}{|c|}{ Case $3: 20 \%$ concentrated sugar solution } \\
\hline Change in liquid level (in m) & Sensor output (nF) & Timer output $(\mathrm{kHz})$ & Frequency to voltage converter output (V) \\
\hline 0.10 & 16.01 & 27.1 & 0.106 \\
\hline 0.20 & 25.5 & 17.0 & 0.148 \\
\hline 0.30 & 37.27 & 11.7 & 0.216 \\
\hline 0.40 & 48.08 & 9.0 & 0.277 \\
\hline 0.50 & 58.7 & 7.3 & 0.336 \\
\hline \multicolumn{4}{|c|}{ Case $4: 30 \%$ concentrated sugar solution } \\
\hline Change in liquid level (in m) & Sensor output $(F)$ & Timer output $(\mathrm{kHz})$ & Frequency to voltage converter output (V) \\
\hline 0.10 & 14.48 & 30.2 & 0.110 \\
\hline 0.20 & 23.32 & 18.5 & 0.173 \\
\hline 0.30 & 34.63 & 12.5 & 0.227 \\
\hline 0.40 & 44.89 & 9.7 & 0.289 \\
\hline 0.50 & 55.78 & 7.8 & 0.348 \\
\hline
\end{tabular}

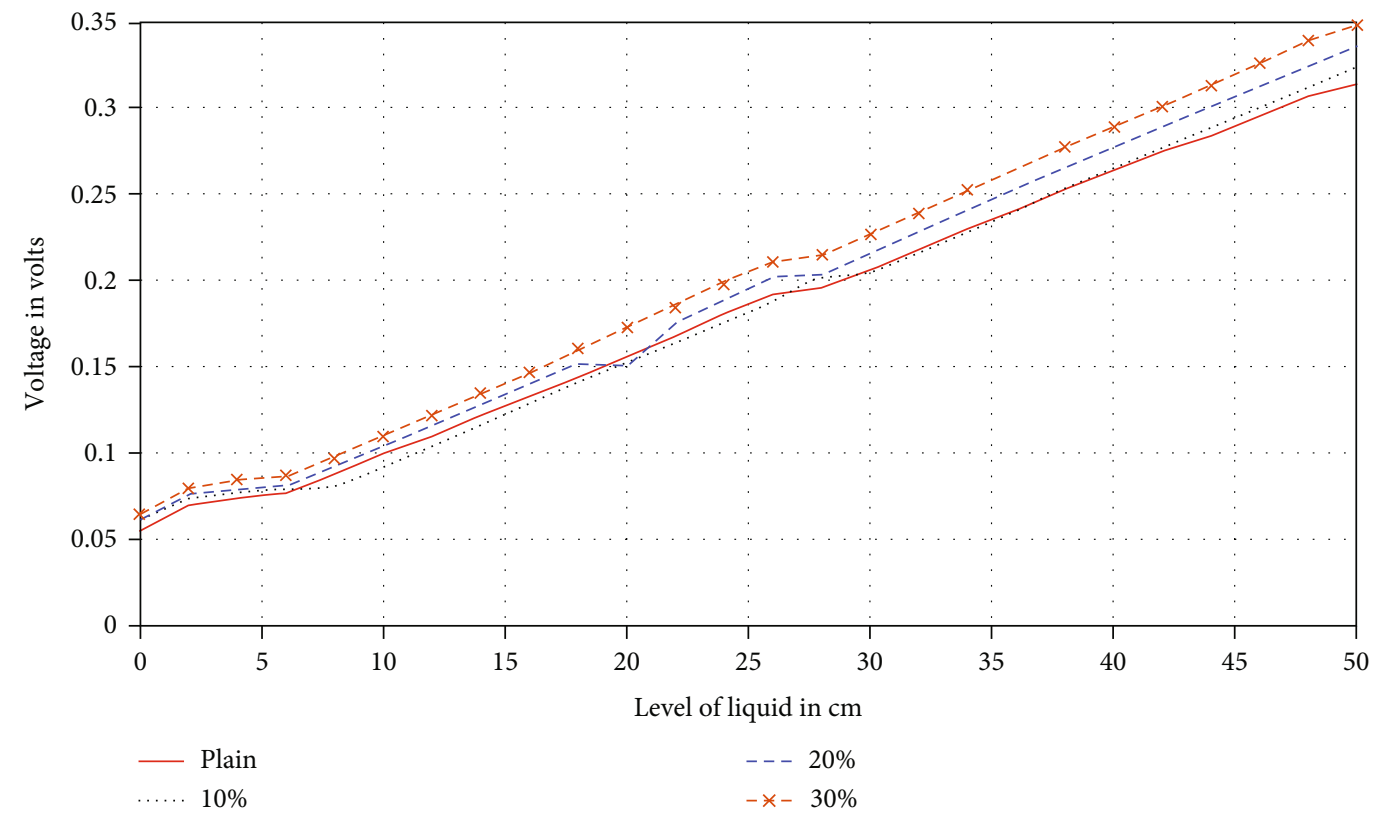

FIGURE 8: Plot of variation of CLS output for variation in the concentration of sugar solution. 


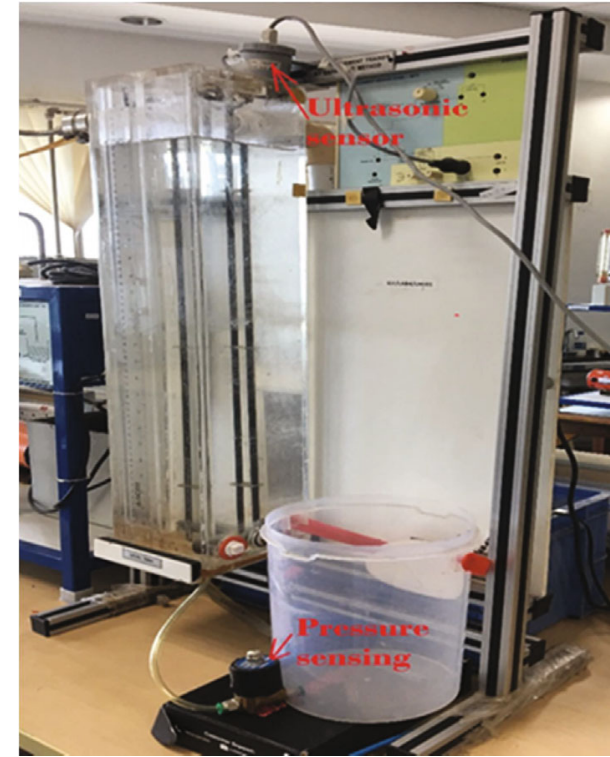

FIgURE 9: Process setup with multiple physical sensors.

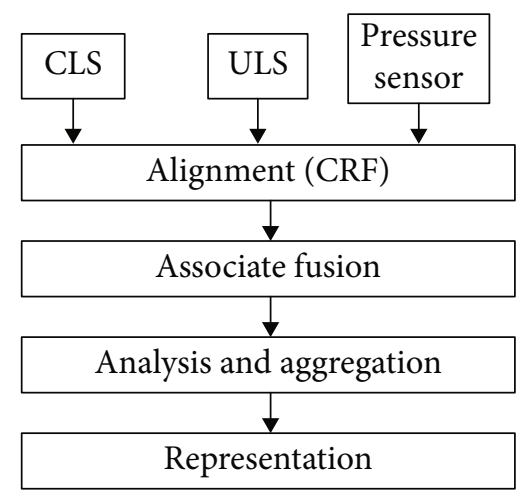

Figure 10: Pau's framework.

stage, it is seen that the data to be fused will be of the same magnitude and be dimensionless.

\subsection{Additional Sensors}

(1) Ultrasonic Level Sensor. Transit time ultrasonic level sensor (ULS) is used to measure the level of the liquid. An ultrasonic level sensor is placed on top of the container such that the wave is transmitted on the surface of the water and the reflected signal is captured back. The time taken for the signal to transmit and reflect is used to compute the level of the liquid. Timer port of the microcontroller is used to compute the travel time, and the output corresponding to the time is transmitted in the form of a 16-bit digital signal. This 16-bit data relating to the liquid level is acquired by the standalone NI myRIO
(2) Capacitive Pressure Sensor. Capacitance pressure sensor (CPS) output varies with a change in input pressure. As the liquid height varies, the pressure created at the nozzle varies. Liquid pressure is more when the liquid level is high and the pressure reduces accordingly as the liquid level in the tank reduces. This change in pressure also varies with variation in liquid density. Table 3 shows the variations of density on variation in the concentration of sugar. The experimental setup consists of a storage tank with dimension $12 \mathrm{~cm} \times 10 \mathrm{~cm} \times 60 \mathrm{~cm}$. From Table 3, it is very evident that there is variation in liquid density for a varying concentration of sugar. The change in pressure induces the change in a physical dimension of the diaphragm used in CPS, causing a relative change in capacitance. This change in capacitance is converted to a voltage using a De Sauty bridge followed by a rectifier circuit. The voltage output from the rectifier is acquired by the analog channel of NI myRIO as shown in Figure 11. From Figure 11, it can be seen that the nonlinearity exists in the characteristics due to the accuracy of discrete components and would be compensated at the time of fusion using artificial neural networks

4.2. Alignment Techniques. Now that data from all three sensors (CLS, ULS, and pressure sensor) is acquired on to a NI myRIO board, they need to be fused and processed. The first step towards fusion is the alignment technique/common representation format. The purpose of this stage is to make sure that all the sensor sources are equally prioritized in terms of its magnitude. This implies that all the signals are directed to dimensionless values ranging from 0 to 1 or 0 to $100 \%$. In the proposed work, we consider it to be between 0 and 1 . Since the data derived from all three sources are one-dimensional, radiometric normalization technique is implemented.

(1) Alignment Technique for CLS Output. Capacitance level sensor with a data conversion circuit produces an output that is a change in voltage for a change in the liquid level. The voltage varies from $0.05 \mathrm{~V}$ to $0.35 \mathrm{~V}$ for a corresponding change in liquid level of $0 \mathrm{~cm}$ to $50 \mathrm{~cm}$. A spatial transformation is used in the proposed work to convert the signal strength in the range of 0 to 1 . For carrying out the spatial transformation, a signal level of $0.05 \mathrm{~V}$ is considered as a reference and using this point, the rest of the signal is computed

(2) Alignment Technique for ULS Output. Timer data corresponding to the transmission time of the ultrasonic signal that represents the liquid level is converted to a range of 0 to 1 . For this, we use spatial alignment technique where the time taken for the wave to transmit and reflect when the tank is full is considered as " 0 " and when the tank is empty it is considered as "1." Intermediate values are extrapolated based on the time taken for a signal to transmit and reflect 
TABLE 3: Change in density for variation in liquid concentration.

\begin{tabular}{ccccc}
\hline & Plain solution in $\mathrm{kg} / \mathrm{m}^{3}$ & $10 \%$ concentration in $\mathrm{kg} / \mathrm{m}^{3}$ & $20 \%$ concentration in $\mathrm{kg} / \mathrm{m}^{3}$ & $30 \%$ concentration in $\mathrm{kg} / \mathrm{m}^{3}$ \\
\hline Density & 1001 & 1053 & 1118 & 1156 \\
\hline
\end{tabular}

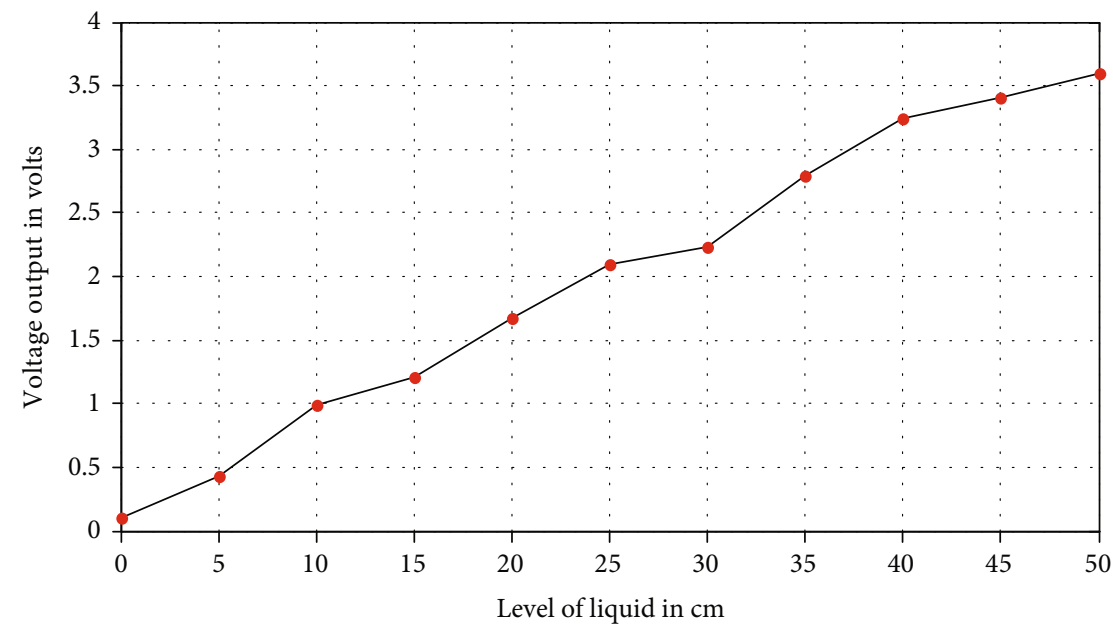

FIGURE 11: Output of capacitance pressure sensor of signal conversion output.

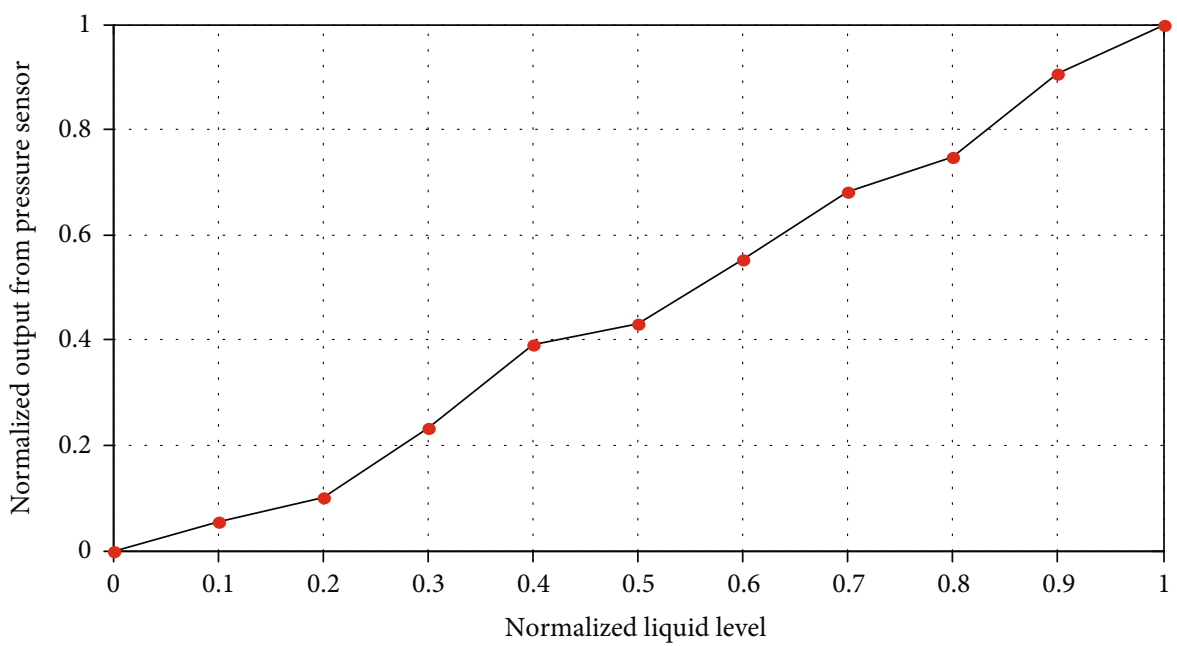

FIGURE 12: Output of capacitance pressure sensor CRF output.

TABLE 4: Neural network parameters.

\begin{tabular}{lc}
\hline Input layer & 6 neurons \\
Output layer & 8 neurons \\
Hidden layers & 7 neurons \\
$R$ & 6 neurons \\
MSE & 0.98 \\
Transfer function & $0.65 E-7$ \\
\hline
\end{tabular}

(3) Alignment Technique for Pressure Sensor Output. The output of the pressure sensor is the voltage varying from $0.1 \mathrm{~V}$ to $3.6 \mathrm{~V}$, as seen from the input-output relation from Figure 11. To represent this data in terms of normalized value between 0 and 1 as shown in Figure 12, min-max expression as represented in Equation (5) is used.

$$
Y_{\text {norm }}=\frac{y_{\max }-y}{y_{\max }-y_{\min }} * 100
$$

4.3. Association Fusion. Association is a technique, where data is grouped into different clusters over the entire range of inputs to perform computation in relation to the objective. The cluster is grouped such that the contribution of that particular cluster of data towards achieving the objective function can be computed. Several functions like the nearest 


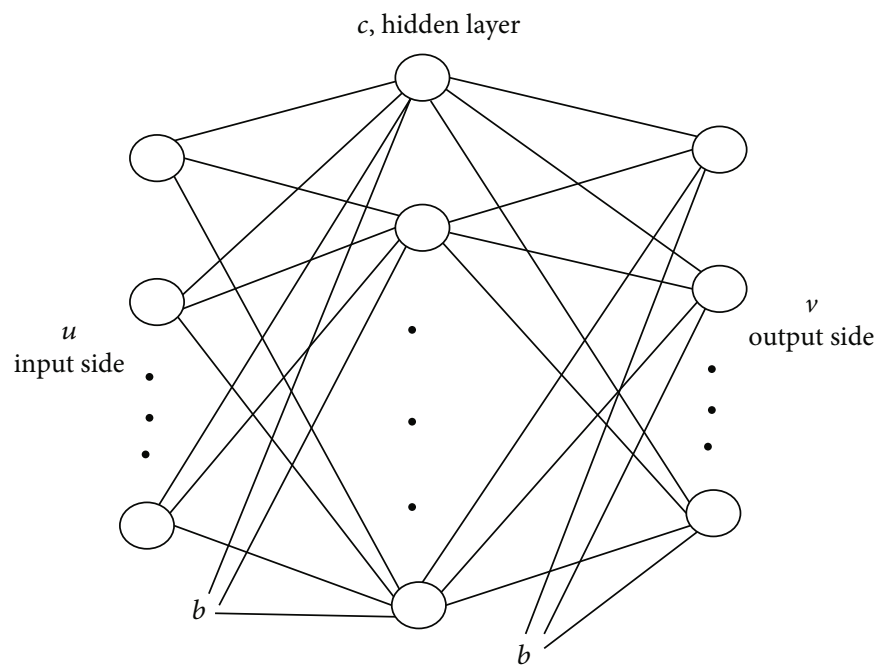

Connection matrix Connection matrix

P1

P2

FIGURE 13: Neural network connectivity and structure.

TABLE 5: Results of water level measurement with varying sugar concentrations.

\begin{tabular}{|c|c|c|c|c|}
\hline Sl. no. & $\begin{array}{l}\text { Actual level of } \\
\text { liquid in } \mathrm{cm}\end{array}$ & $\begin{array}{l}\text { Actual sugar in gram } \\
\text { per litre of water }\end{array}$ & $\begin{array}{c}\text { Measured level of } \\
\text { liquid in } \mathrm{cm}\end{array}$ & $\begin{array}{c}\text { Measured sugar in } \\
\text { gram per litre of water }\end{array}$ \\
\hline 1 & 0 & 0 & 0.06 & 0.09 \\
\hline 2 & 2 & 2.5 & 2.14 & 2.65 \\
\hline 3 & 4 & 3.6 & 3.85 & 3.54 \\
\hline 4 & 6 & 4.8 & 5.65 & 5.12 \\
\hline 5 & 8 & 10.0 & 8.19 & 9.93 \\
\hline 6 & 10 & 7.6 & 9.89 & 7.75 \\
\hline 7 & 12 & 13.5 & 11.89 & 13.21 \\
\hline 8 & 14 & 17.5 & 14.02 & 17.65 \\
\hline 9 & 16 & 25.0 & 15.91 & 24.61 \\
\hline 10 & 18 & 8.5 & 17.88 & 8.32 \\
\hline 11 & 20 & 15.5 & 20.1 & 15.39 \\
\hline 12 & 22 & 21.0 & 21.5 & 20.84 \\
\hline 13 & 24 & 1.0 & 23.59 & 0.94 \\
\hline 14 & 26 & 5.0 & 25.9 & 5.21 \\
\hline 15 & 28 & 19.0 & 28.01 & 19.34 \\
\hline 16 & 30 & 23.5 & 30.09 & 23.04 \\
\hline 17 & 32 & 6.0 & 31.82 & 5.87 \\
\hline 18 & 34 & 14.0 & 33.69 & 14.42 \\
\hline 19 & 36 & 17.2 & 35.71 & 17.51 \\
\hline 20 & 38 & 11.0 & 38.05 & 11.11 \\
\hline 21 & 40 & 22.0 & 39.82 & 21.81 \\
\hline 22 & 42 & 17.0 & 41.8 & 16.74 \\
\hline 23 & 44 & 2.5 & 43.95 & 2.52 \\
\hline 24 & 46 & 10.0 & 45.82 & 10.12 \\
\hline 25 & 48 & 20.0 & 47.95 & 19.63 \\
\hline 26 & 50 & 0 & 49.78 & 0.03 \\
\hline
\end{tabular}




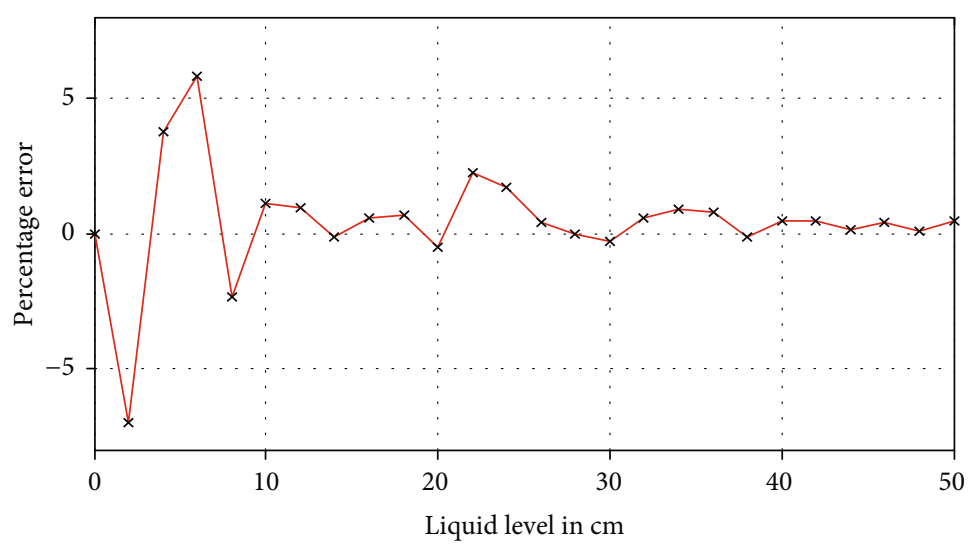

FIGURE 14: Error characteristics for liquid level measurement of sugar syrup.

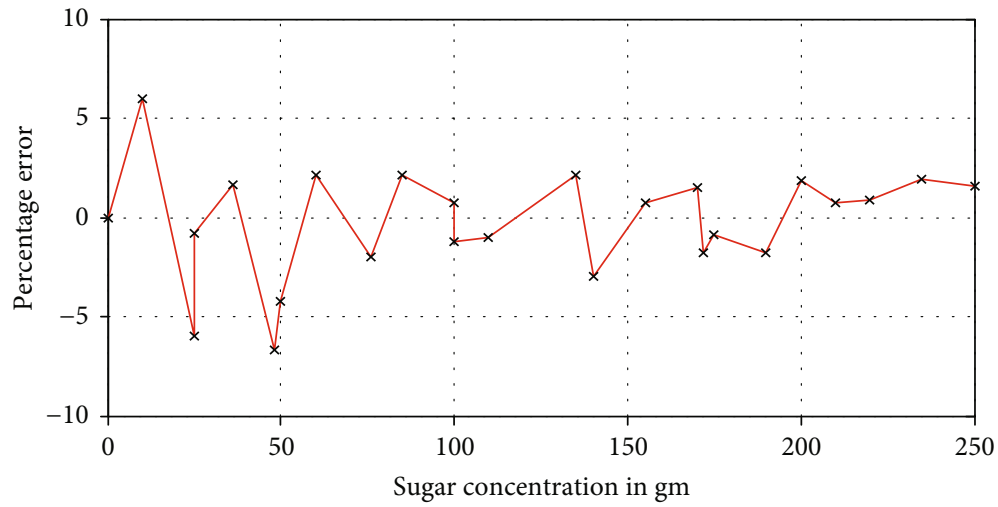

FIGURE 15: Error characteristics for concentration analysis of sugar syrup.

neighbourhood, boundary conditions, the binary tree, and kd tree are used for this purpose. In the proposed work, boundary condition algorithms are used on CLS data; kd tree algorithm is used on pressure sensor data, followed by the nearest neighbourhood algorithm for ULS data.

4.4. Analysis and Aggregation or Decision-Making Process. The decision-making step in the proposed work involves the computation of the liquid level independent of the liquid used to determine the concentration of the solution. In the proposed work, evidence matching technique is used. For carrying out evidence matching, the neural network algorithm [45] is used. For training neural network, data corresponding to varying liquid levels with a defined concentration of solvent is considered. Here, 50 grams, 100 grams, 150 grams, and 200 grams of sugar are added to every 10 litres of water.

The input data for the neural network block is from the association vector, each of which is derived from the capacitance level sensor, pressure sensor, and ultrasonic level sensor. The neural network algorithms are trained such that the information related to the liquid level is derived directly from the ultrasonic level sensor output. For the information corresponding to the addition of liquid, CLS and pressure sensor data are used. Since it is clearly demonstrated that CLS output depends on the level of liquid and type of liquid (permittivity of liquid), the pressure sensor output depends on the density of the liquid (volume and mass). Backpropagation network with artificial bee colony algorithm is used in the proposed work. Backpropagation network can be decomposed into a feed-forward computation, backpropagation to the output layer, backpropagation to the hidden layers, and weight updates. Table 4 shows the details regarding the neural network model implemented in the proposed work. Pictorial representation of neural network signal connectivity is shown in Figure 13.

Weight of the first connection matrix is given by $\mathrm{P} 1=\mathrm{PU}+1, c$. Similarly, the weight of the second connection matrix is given by $\mathrm{P} 2=\mathrm{Pc}+1, v$, since there will be $(u+1) * c$ weights between the input side and hidden layers and, similarly, $(c+1)^{*} v$ weights in between hidden layers and output side. By considering the association vector for three transducer signals as $f=(f 1, f 2 \cdots f u)$, the excitation $g_{i}$ for the $i$ th hidden unit is given by

$$
g_{i}=\sum_{j=1}^{u+1} P_{i j} \widehat{f}_{j}
$$


TABLE 6: Results of water level measurement with varying milk powder concentrations.

\begin{tabular}{|c|c|c|c|c|}
\hline Sl. no. & $\begin{array}{l}\text { Actual level of } \\
\text { liquid in } \mathrm{cm}\end{array}$ & $\begin{array}{l}\text { Actual milk powder in } \\
\text { gram per litre of water }\end{array}$ & $\begin{array}{l}\text { Measured level of } \\
\text { liquid in } \mathrm{cm}\end{array}$ & $\begin{array}{l}\text { Measured milk powder in } \\
\text { gram per litre of water }\end{array}$ \\
\hline 1 & 0 & 0 & 0 & 0.10 \\
\hline 2 & 4 & 45 & 3.7 & 44.5 \\
\hline 3 & 10 & 85 & 10.1 & 87.8 \\
\hline 4 & 10 & 10 & 9.4 & 10.4 \\
\hline 5 & 15 & 100 & 14.8 & 97.6 \\
\hline 6 & 18 & 60 & 17.1 & 61.4 \\
\hline 7 & 18 & 35 & 17.8 & 34.1 \\
\hline 8 & 25 & 75 & 26.4 & 73.6 \\
\hline 9 & 30 & 50 & 30.9 & 48.9 \\
\hline 10 & 30 & 85 & 28.9 & 85.1 \\
\hline 11 & 34 & 55 & 35.6 & 55.1 \\
\hline 12 & 42 & 10 & 40.1 & 9.7 \\
\hline 13 & 42 & 90 & 41.4 & 89.5 \\
\hline 14 & 42 & 0 & 43.7 & 0.23 \\
\hline 15 & 45 & 70 & 45.9 & 73.7 \\
\hline 16 & 48 & 25 & 50.0 & 24.5 \\
\hline 17 & 48 & 60 & 50.0 & 58.9 \\
\hline 18 & 50 & 40 & 50.0 & 39.2 \\
\hline 19 & 50 & 12 & 48.3 & 12.7 \\
\hline 20 & 50 & 100 & 49.1 & 100 \\
\hline
\end{tabular}

Considering the sigmoid " $s$ " as the activation function, a forward vector is computed.

$$
f_{i}=s\left(\sum_{j=1}^{u+1} P_{i j} \widehat{f}_{j}\right) .
$$

In the backward path, from the output of the network, the computation is similarly reversed such that the error is minimized. Artificial bee colony algorithm is used to update the weights " $P$." Training is carried out until the network produces target as per the objective. This is achieved by monitoring the value of regression " $R$ " which should ideally be one and mean square error "MSE" which should ideally be zero.

4.5. Representation. At this stage, the data is converted to the form of a physical variable. Until this stage, computation was carried out with a dimensionless value in the range of 0 to 1 . The result obtained from the neural network will also be in the range of 0 to 1 which can be difficult to interpret by the user. Therefore, it is imperative to represent the results in the form of liquid level in terms of "cm" and concentration of the liquid in terms of "grams per litre."

\section{Results and Discussion}

Once the process of data fusion is complete, the performance of the reported technique needs to be evaluated. For testing, the liquid level is measured by varying the concentration of sugar used in water and varying the level of the liquid. The level of liquid is varied in the range of 0 to $50 \mathrm{~cm}$, and subse- quently, the concentration of sugar is varied from 0 gram per litre of water to 25 grams per litre of water. Table 5 shows the results obtained for the same.

Measurement of the liquid level is carried out using the designed multisensor technique for a liquid with varying concentrations. Liquid level is measured for different liquid concentrations. In Table 5, the output measured by the instrument for the varied sugar concentration is noted. Liquid level is measured when different liquids are used with varying sugar concentration without any recalibration of the system. In any available instrument, when the process medium is changed an error would be introduced, which is not the case here. The proposed system is used to measure the varying levels of liquid starting from $0 \mathrm{~m}$ to $50 \mathrm{~cm}$ with different liquid concentrations. From Table 5, it can be seen that the proposed technique is able to measure the liquid level with a maximum deviation of $5 \mathrm{~mm}$ from the desired value. The proposed system is also designed to identify the change in concentration using which the additive in the water is measured. The last column of Table 5 shows the measured concentration of sugar in the solution; it is observed that the proposed technique can measure the concentration of sugar added with the maximum deviation of $400 \mathrm{mg}$ from the actual value.

The characteristics in terms of percentage error for the measurement are obtained and are plotted in Figures 14 and 15 for level measurement and concentration analysis. It is seen that the maximum percentage error produced by the measurement system is around $7 \%$.

To evaluate the performance, measurement is carried out considering milk powder instead of sugar. The results 


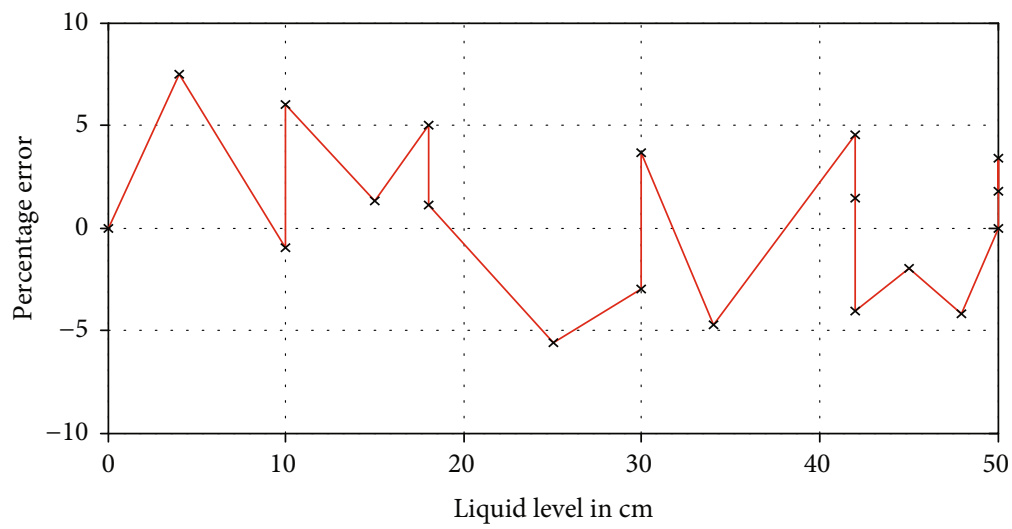

FIGURE 16: Error characteristics for liquid level measurement of milk.

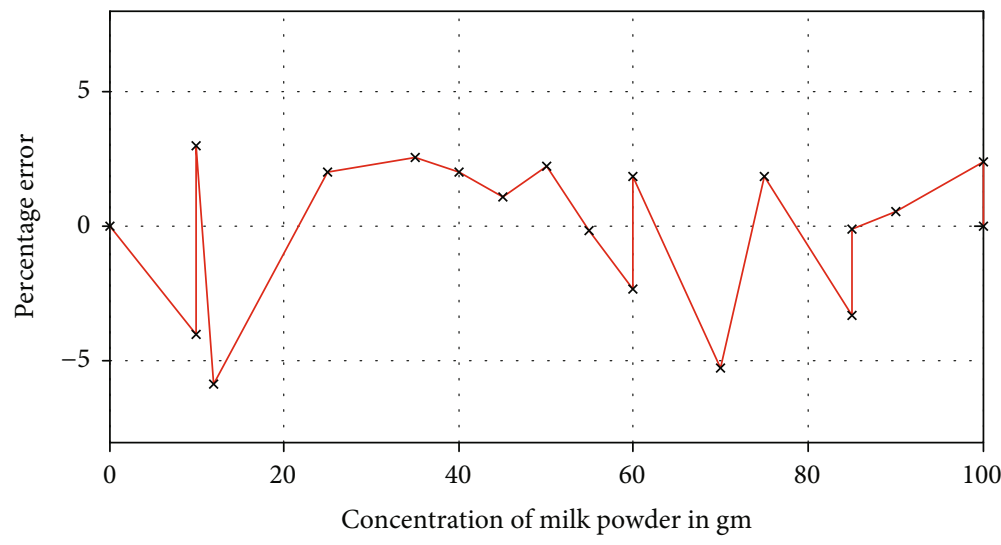

FIgURE 17: Error characteristics for concentration analysis of milk powder.

obtained for the test conducted are shown in Table 6. For the measurement of liquid level, a range of $0 \mathrm{~cm}$ to $50 \mathrm{~cm}$ is considered and the concentration of milk powder in water is varied from 0 grams to 100 grams per litre of water. Error characteristics are plotted in Figures 16 and 17.

Similar to the experiment with the sugar solution, the proposed system is subjected to testing by considering the milk solution to validate the proposed measurement technique. Similar to the previous experiment, the results show a maximum deviation of $1 \mathrm{~cm}$ for the liquid level measured and a maximum deviation of $3 \mathrm{gm} / \mathrm{litre}$ for the measured concentration as compared to the actual values.

From Tables 5 and 6 and Figures 14-17, it is seen that the reported multisensor technique is able to measure liquid level accurately and robustly without the influence of additives in the liquid. The concentration of the additives was also measured accurately. Further tests were conducted under different conditions (different concentrations of additives and liquid level) with approximately 260 samples in addition to the results shown in Table 5 and Table 6 . Root mean square of percentage error from the reported measurement technique was found to be $1.1 \%$.

\section{Conclusion}

The level process is one of the widely used industrial processes, indicating a need for accurate measurement. Accuracy in measurement can be only be achieved if the process can produce results with the highest resistance to noise. Here, the noise is the additives in liquid. To achieve this, a technique comprising of multiple sensors fused together is suggested. For this purpose, a capacitive level sensor, an ultrasonic level sensor, and a pressure sensor are used. The output from each of the sensor is converted to a standard signal with the help of the data conversion circuit. The obtained signals are processed in four stages: alignment, association, analysis, and representation. Test results produced by the reported technique clearly indicate that the measurement is accurate and robust. Root mean square percentage error value of $1.1 \%$ indicates that the measurement system can be used in industries. With the use of an additional sensor or an improved training algorithm, this value can be increased. One constraint to this measurement process is that neither the liquid nor the additives can be conductive. Additionally, additives added must be soluble in the liquid.

\section{Data Availability}

The data used to support the findings of this study are included within the article.

\section{Conflicts of Interest}

The authors declare that they have no conflicts of interest. 


\section{References}

[1] A. Kulkarni, R. N. Karekar, and R. C. Aiyer, "Liquid level sensor," Review of Scientific Instruments, vol. 76, no. 10, pp. 105108-105113, 2005.

[2] H. Canbolat, "A novel level measurement technique using three capacitive sensors for liquids," IEEE Transactions on Instrumentation and Measurement, vol. 58, no. 10, pp. 37623768, 2009.

[3] S. V. Balakin, "Errors of level sensors of a fueling level control system of an upper-stage rocket," Measurement Techniques, vol. 58, no. 9, pp. 975-981, 2015.

[4] S. Pal and R. Barik, "Design, development and testing of a semi cylindrical capacitive sensor for liquid level measurement," Sensors and Transducer, vol. 116, no. 5, pp. 13-20, 2010.

[5] G. Zheng, H. Zong, X. Zhuan, and J. Luan, "Fast dynamic liquid level sensor based on liquid resistance," in AFRICON 2007, Windhoek, South Africa, 2007.

[6] S. Chakravarthy, R. Sharma, and R. Kasturi, "Noncontact level sensing technique using computer vision," IEEE Transactions on Instrumentation and Measurement, vol. 51, no. 2, pp. 353-361, 2002.

[7] T. H. Wang, M. C. Lu, C. C. Hsu, C. C. Chen, and J. D. Tan, "Liquid-level measurement using a single digital camera," Measurement, vol. 42, no. 4, pp. 604-610, 2009.

[8] M. G. Lorenz, L. Mengibar-Pozo, and M. A. Izquierdo-Gil, "High resolution simultaneous dual liquid level measurement system with CMOS camera and FPGA hardware processor," Sensors and Actuators A: Physical, vol. 201, pp. 468-476, 2013.

[9] H. K. Singh, S. K. Chakroborty, H. Talukdar, N. M. Singh, and T. Bezboruah, "A new non-intrusive optical technique to measure transparent liquid level and volume," IEEE Sensors Journal, vol. 11, no. 2, pp. 391-398, 2011.

[10] M. Lomer, J. Arrue, C. Jauregui, P. Aiestaran, J. Zubia, and J. M. López-Higuera, "Lateral polishing of bends in plastic optical fibres applied to a multipoint liquid-level measurement sensor," Sensors and Actuators A: Physical, vol. 137, no. 1, pp. 68-73, 2007.

[11] F. Lucklum and B. Jakoby, "Non-contact liquid level measurement with electromagnetic-acoustic resonator sensors," Measurement Science and Technology, vol. 20, no. 12, p. 124002, 2009.

[12] T. Nakagawa, A. Hyodo, K. Kogo, H. Kurata, K. Osada, and S. Oho, "Contactless liquid-level measurement with frequency-modulated millimeter wave through opaque container," IEEE Sensors Journal, vol. 13, no. 3, pp. 926-933, 2013.

[13] R. di Sante, "Time domain reflectometry-based liquid level sensor," Review of Scientific Instruments, vol. 76, no. 9, pp. 095107-095112, 2005.

[14] Y. Liu, Y. Li, X. Yan, and W. Li, "High refractive index liquid level measurement via coreless multimode fiber," IEEE Photonics Technology Letters, vol. 27, no. 20, pp. 2111-2114, 2015.

[15] R. Paul and A. Sengupta, "Design and application of discrete wavelet packet transform based multiresolution controller for liquid level system," ISA Transactions, vol. 71, pp. 585-598, 2017.

[16] K. Loizou and E. Koutroulis, "Water level sensing: state of the art review and performance evaluation of a low-cost measurement system," Measurement, vol. 89, pp. 204-214, 2016.

[17] B. Jin, Z. Zhang, and H. Zhang, "Structure design and performance analysis of a coaxial cylindrical capacitive sensor for liquid-level measurement," Sensors and Actuators A: Physical, vol. 223, pp. 84-90, 2015.

[18] Y. Ran, L. Xia, D. Niu, Y. Wen, C. Yu, and D. Liu, "Design and demonstration of a liquid level fiber sensor based on selfimaging effect," Sensors and Actuators A: Physical, vol. 237, pp. 41-46, 2016.

[19] X. Zhang, W. Peng, Z. Liu, and Z. Gong, "Fiber optic liquid level sensor based on integration of lever principle and optical interferometry," IEEE Photonics Journal, vol. 6, no. 2, pp. 1-7, 2014.

[20] B. Liu, D. Y. Wang, and A. Wang, "Liquid-surface-level sensing based on transverse pulse train technique," IEEE Sensors Journal, vol. 16, no. 8, pp. 2317-2321, 2016.

[21] A. Nakano and T. Nishizu, "Experimental study of liquid level gauge for liquid hydrogen using Helmhotz resonance technique," Cryogenics, vol. 7, pp. 41-48, 2016.

[22] C. S. A. Gong, H. K. Chiu, L. R. Huang, C. H. Lin, Z. D. Hsu, and P. H. Tu, "Low-cost comb-electrode capacitive sensing device for liquid-level measurement," IEEE Sensors Journal, vol. 16, no. 9, pp. 2896-2897, 2016.

[23] H.-X. Zhang, Y.-L. Hou, L.-S. Feng et al., "Polymer optical fiber continuous liquid level sensor for dynamic measurement," IEEE Sensors Journal, vol. 15, no. 9, pp. 5238-5242, 2015.

[24] M. A. Karimi, M. Arsalan, and A. Shamim, "A low cost, printed microwave based level sensor with integrated oscillator readout circuitry," in 2017 IEEE MTT-S International Microwave Symposium (IMS), pp. 1742-1745, Honololu, HI, USA, 2017.

[25] X. Chi, X. Ke, and W. Xu, "Optical fibre liquid sensor for cryogenic propellant mass measurement," Electronics Letters, vol. 55, no. 5, pp. 278-280, 2019.

[26] R. Nie, W. Guo, Y. Luo, W. Li, M. Xia, and K. Yang, "Optical liquid-level sensor based on a designed light guide plate," Sensors and Actuators A: Physical, vol. 296, pp. 352-356, 2019.

[27] T. Islam, S. A. Khan, M. F. A. Khan, and S. C. Mukhopadhyay, "A relaxation oscillator-based transformer ratio arm bridge circuit for capacitive humidity sensor," IEEE Transactions on Instrumentation and Measurement, vol. 64, no. 12, pp. 34143422, 2015.

[28] E. J. Mohamad, R. A. Rahim, M. H. F. Rahiman, H. L. M. Ameran, Y. A. Wahab, and O. M. F. Marwah, "Analysis of crude palm oil composition in a chemical process conveyor using electrical capacitance tomography," Flow Measurement and Instrumentation, vol. 50, pp. 57-64, 2016.

[29] K. A. Thomas, S. Nair, A. R. Kumar, V. Natarajan, and R. John, "Application of fringe field capacitance sensor for the study of water permeation in organic coatings," Journal of Coatings Technology and Research, vol. 13, no. 5, pp. 829-835, 2016.

[30] A. Fuchs, H. Zangl, and G. Holler, "Capacitance-based sensing of material moisture in bulk solids: applications and restrictions," in Smart Sensor and Sensing Technology, S. C. Mukhopadhyay and G. S. Gupta, Eds., pp. 235-248, Springer, Berlin, Heidelberg, 2008.

[31] C. Tan, P. Li, W. Dai, and F. Dong, "Characterization of oilwater two-phase pipe flow with a combined conductivity/capacitance sensor and wavelet analysis," Chemical Engineering Science, vol. 134, pp. 153-168, 2015.

[32] L. Zhai, N. Jin, Z. Gao, and Z. Wang, "Liquid holdup measurement with double helix capacitance sensor in horizontal oil- 
water two-phase flow pipes," Chinese Journal of Chemical Engineering, vol. 23, no. 1, pp. 268-275, 2015.

[33] K. Asencio, W. Bramer-Escamilla, G. Gutiérrez, and I. Sánchez, "Electrical capacitance sensor array to measure density profiles of a vibrated granular bed," Journal of Powder Technology, vol. 270, 19 pages, 2015.

[34] K.-W. Park and H. C. Kim, "High accuracy pressure type liquid level measurement system capable of measuring density," in TENCON 2015 - 2015 IEEE Region 10 Conference, Macao, China, 2015.

[35] J.-Y. Kim, J.-H. Lee, S.-E. Bae et al., "Automated hightemperature liquid level measurement system using a dynamic tube pressure technique," Journal of Industrial and Engineering Chemistry, vol. 49, pp. 30-35, 2017.

[36] C. Li, T. Ning, C. Zhang et al., "Liquid level measurement based on a no-core fiber with temperature compensation using a fiber Bragg grating," Sensors and Actuators A: Physical, vol. 245, pp. 49-53, 2016.

[37] K. V. Santhosh and B. K. Roy, "A practically validated adaptive calibration technique using optimized artificial neural network for level measurement by capacitance level sensor," Measurement and Control, vol. 48, no. 7, pp. 217-224, 2015.

[38] S. Woeckel, H. Arndt, U. Steinmann, J. Auge, and R. Lucklum, "Acoustic clamp-on liquid level detection in case of transducer misalignment," Procedia engineering, vol. 120, pp. 1201-1204, 2015.

[39] S. Liu, J. Tian, N. Liu, J. Xia, and P. Lu, “Temperature insensitive liquid level sensor based on anti-resonant reflecting guidance in silica tube," Journal of light wave technology, vol. 34, no. 22, pp. 5239-5243, 2016.

[40] B. Liptak, Instrument Engineers Handbook, CRC Press, 4th Edition edition, 2004.

[41] D. V. S. Murty, Transducer and Instrumentation, PHI, 2008.

[42] Y. Iossel, E. Kochanov, and M. Strunskii, The Calculation of Electrical Capacitance, Ft. Belvoir: Defense Technical Information Center, 1971.

[43] S. Franco, Design with Operational Amplifiers and Analog Integrated Circuits, McGraw-Hill, New York, 2002.

[44] H. B. Mitchell, An Introduction - Multi-Sensor Data Fusion, Springer, 2007.

[45] L. Fausett, Fundamentals of Neural Network: Architecture, Algorithms and Application, Pearson Education, 2004. 


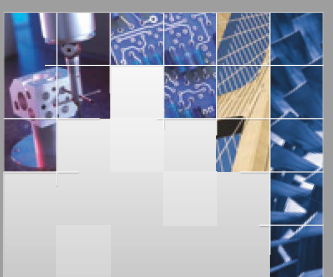

\section{Enfincering}
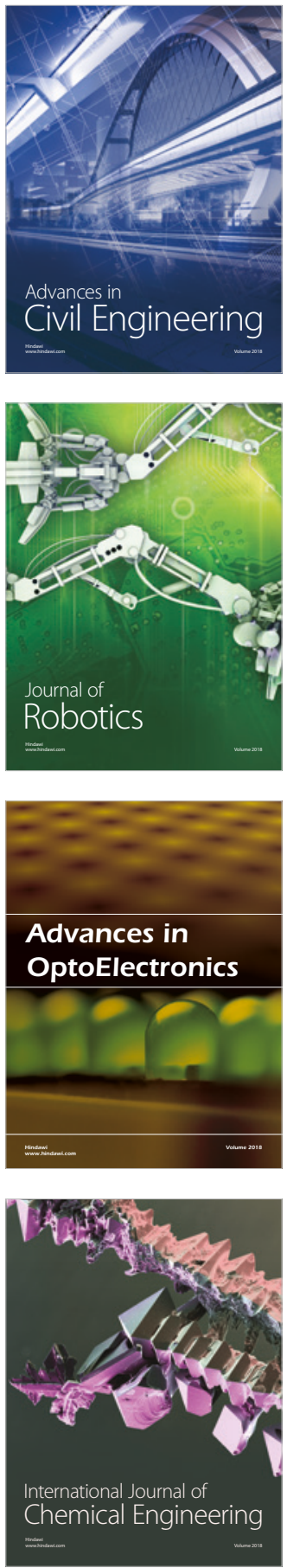

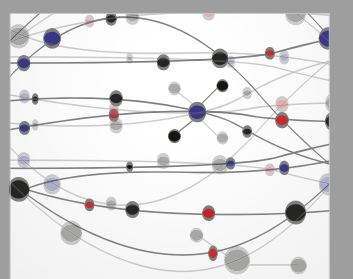

\section{Rotating \\ Machinery}

The Scientific World Journal

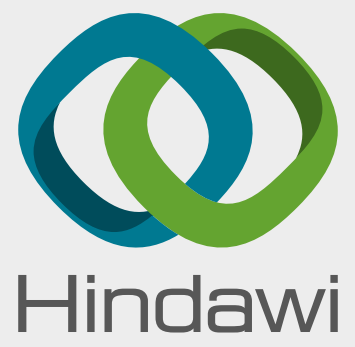

Submit your manuscripts at

www.hindawi.com
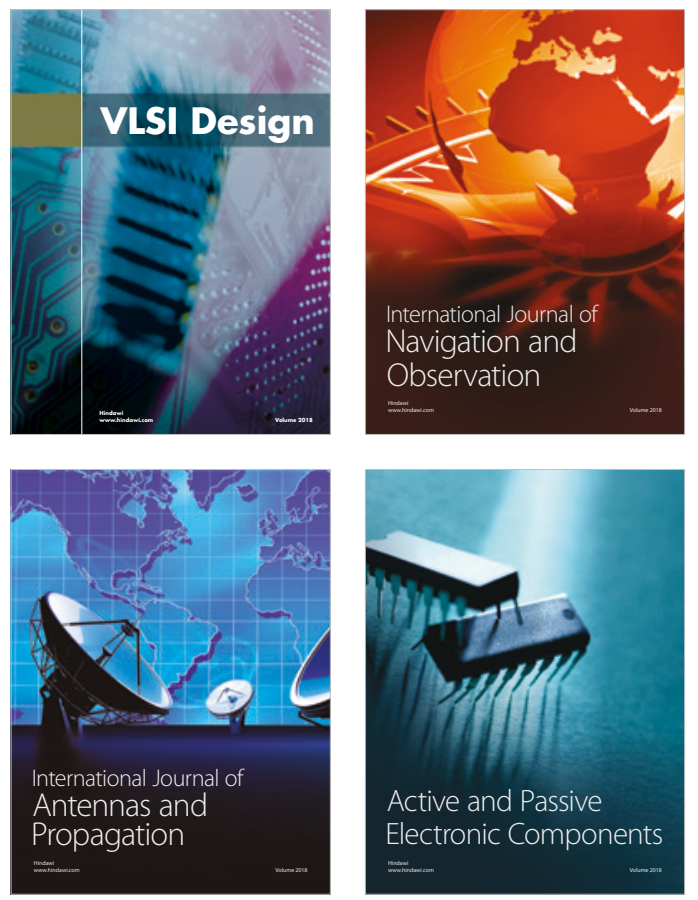
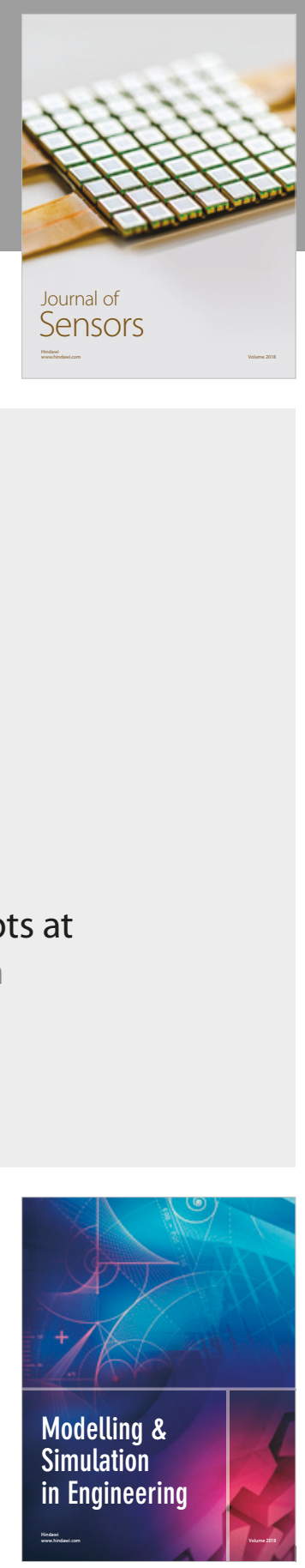

\section{Advances \\ Multimedia}
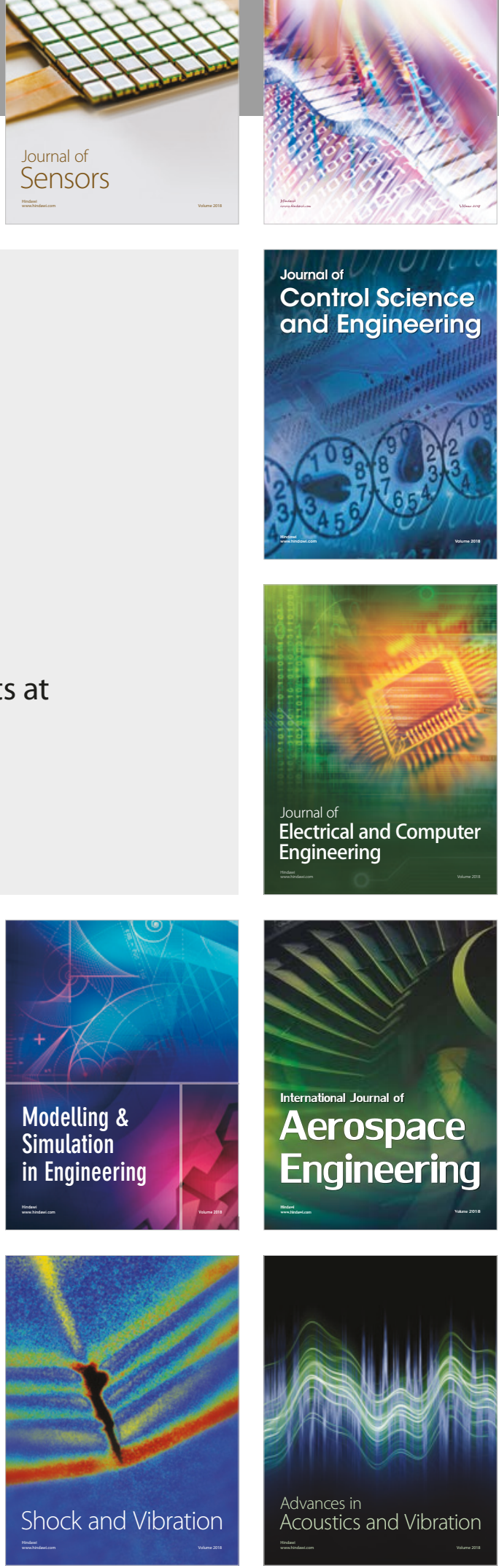